\title{
Cardiac surgery: the infinite quest
}

\author{
Cirurgia cardíaca: a busca infinita
}

\author{
Rodolfo A. Neirotti ${ }^{1}$
}

DOI: $10.5935 / 1678-9741.20120104$

RBCCV 44205-1429

\section{INTRODUCTION}

Man's Search for Meaning

"The secret of life is to have a task, something you devote your whole life to, something you bring everything to every minute of the day for your whole life. And the most important thing is - it must be something you cannot possibly do!"’ Henry Moore

What are these series of articles about? Hopefully the readers can find in them a series of concepts and their potential applications to daily practice - some borrowed from my previous work and some from others, in an attempt to expand the horizon of my knowledge. Although I have already presented and written on these subjects, the aim in returning to some of them, as well as adding new ones, is not just to offer new information but more importantly to propose some provocative viewpoints and theories for everyone involved with each and every encounter. I am challenging the reader in the belief that a continuous reassessment of our thoughts and convictions by defying reality can be helpful to verify the sustainability of previous judgments: "By studying how new observations led to the revision of important theories one can see that science is not about immutable laws but provisional explanations that get revised when a better one comes along." The

1. MD, MPA, PhD, FETCS, Honorary Member of the Brazilian Society of Cardiovascular Surgery. repeated 'trial' of a certain event is precisely what leads to new understandings — which in turn can instigate even newer understandings [1].

When Albert Einstein wrote "The significant problems we face cannot be solved at the same level of thinking we were at when we created them" he was suggesting that if we always think the way we have always thought, we will always do what we have always done, and if we advocate and do what we have always done, we will get what we have always gotten - stagnation of thinking. In addition, his observation remains us of the need to reflect on the issues, challenges, and opportunities in front of the profession and specialty - a future that most likely will be quite different from the recent past. "History is where the future begins" [2]. "You only look to the past to create a solution for the future. If you look down, you can only see a few feet, but if you look up, the view is infinite" [3].

As J. Matloff put it, "The future of medicine would evolve almost entirely as a function of leadership and management capabilities. Beyond whether this evolution could happen, concern was expressed having to do with where that leadership would emerge from government, business, or medicine" [4]. Therefore, it is important that physicians and health professionals take an active role in the political, economic, and social aspects of society social cure - in order to defend the interests of those suffering. The time has come when those involved have to decide if they will continue to be a part of the problem, or

Correspondence address:

1199 Beacon St, Unit 2.

Brookline, MA 02446

USA

Email: RA_Neirotti@ksg06.harvard.edu 


\begin{tabular}{|ll|}
\hline Abbreviations, Acronyms and Symbols \\
\hline OECD & $\begin{array}{l}\text { Organization for Economic Co-operation and } \\
\text { Development }\end{array}$ \\
\hline
\end{tabular}

whether they will be part of the solution delving more into potential answers to improving their institutions and as a result the troubled health care system.

In recent visits to some leading centers I was able to perceive that they are already applying many of the concepts that will be discussed in the different sections. Like in the universe, in the world of pediatric cardiac surgery there are visible galaxies emitting light and five times as much dark matter. The purpose of introducing theories and ideas from other disciplines attempts to lighting up - if that is the appropriate word - the dark matter of our specialty and if possible contribute to diminish its size.

Because of its length, the manuscript will be divided in three parts that will be published in consecutive issues of the Journal, following the suggestion of the Editor.

\section{PART I}

\section{Approaching our profession and specialty in new and different ways}

Ultramini-abstract: Thinking of the big picture matters because the health care is multidimensional and therefore it is affected by the economy, social issues and politics, particularly in the developing world. An array of topics will be discussed for the sake of a better understanding of subtleties and depths of the problem. The purpose of combining a mix of ideas and perspectives intended to avoid a piece structured around narrow fields of view.

\section{THE CHALLENGE}

How do we generate the necessary cohesion to implement reforms? We need to transform exogenous ideas into endogenous dreams through leadership, persuasion, and empowerment. By breaking down complexity into individuals, activities, connections, and pathways, it should be possible to act on the different levels, particularly on individuals to build the system of work required in successful organizations. Since institutions are defined not by buildings, endowments, or traditions but by people with vision, an effort should be made to attract the most talented people that can be found, never ending the pursuit of that perfect candidate. I invite the reader to share my vision rejecting the formalism that continuously hinders our perception and at the same time I encourage them to keep their eyes open.

In general, people with the ideas do not have the power to implement them, whereas the people with the power are so embedded in the system that they are unlikely to come up with new thoughts. In addition, it is important to bear in mind the principle-policy/implementation gap - an important barrier to modernization nicely explained by the public choice theory, which results in fewer implementations - just $10 \%$ of good ideas. Often, people tend to agree when principles and policies are discussed but the support diminishes when those bearing the costs - interest groups, more influential than those who would benefit from action - have rational incentives to do precisely what they are doing even though the want of the greater part is differing. "The politician becomes a statesman when he thinks of the next generation and not in the next election." Winston Churchill (1874 - 1965)

\section{Thoughts on changes brings possibilities - but also pains "Inflexible mentality remains the biggest stumbling block to change" Mikhail Gorbachev}

In almost every system - country, government, community, organization - there is something broken, flawed or maladaptive. The diagnostic challenge of leadership is to establish what aspects of the system are broken, defective, or maladaptive and the extent to which those features exist in the values, habits, practices and priorities of the people [5].

What is it about how our brains are wired that resists change so tenaciously? Why do we fight even what we know to be in our own vital interests? Resistance of people to change and human nature's tendency to apply the "minimal risk" and "least effort" strategies that result in incomplete adaptive work allowing subsistence but no optimal result, explain the frequency and persistence of maladaptive practices. Maladaptive practices eventually become permanent adaptive challenges that do not subside with the application of technical skills provided by a profession because people are unwilling to probing their values, habits, practices and priorities. The values and practices that might be viewed as weaknesses are those values and practices that people adhere to and in doing so stay away from dealing with reality. Instead of scrutinizing these features, they prefer to look outside their structure for the cause of what is erroneous. Yet, solutions often reside not in the executive suite but in the collective intelligence of employees at all levels, who need to use one another's resources, and learn their way to those solutions. The answer is leadership, an important component of the leadership/ management philosophy that fosters transformation by encouraging creative thinking, challenging the status quo, 
removing barriers and promoting "bottom up" changes. To think creatively means to think "outside the box." That kind of thinking needs role models, whom we count on to bring us new visions and possibilities [5].

It is difficult to discuss the future with people who live in the present, but even more so if they live in the past. Cultural stagnation, based on the sameness of world view caused by social, intellectual, educational, and professional inbreeding, is a real problem and a barrier to progress. These are people who travel in the same circles, go to the same parties, talk to the same people, compare their ideas to people with the same ideas, and develop a standard view on issues that make any deviation from them seem somehow marginal, or even weird. Everybody must believe the same things they do — thinking stagnation without diversity of thoughts - or their contributions will not be constructive. Opposite poles have always more to say to each other than people who share exactly the same views. "You don't make peace with friends. You make it with very unsavory enemies." Isaac Rabin, former Prime Minister of Israel.

Suggestion: be receptive to changes and new ideas allow yourself to be changed!

Complex change requires vision, skills, incentives, resources, and an action plan. In addition, a framework for problem diagnostics may be necessary to identify the changes and adaptive work required according to context throughout the system. When goals and objectives have been achieved, and successful change has occurred, it is important for the institution to recognize, celebrate, and if possible reward these accomplishments.

In summary, "It is not the strongest of the species that survive, nor the most intelligent, but the one most responsive to change"-Charles Darwin

\section{The Health Care}

Public health is a system of systems: The health care system goes beyond the care supply system which includes doctors, nurses and hospitals. It also brings in government infrastructure, business, university circles, society and media. It seems to be difficult to get all of those involved to agree on the best way to improve this intricate milieu. Reinventing ourselves can contribute to the reinvention of the public health domain. The "Fine Art of Reinvention" means specifically taking something that already exist and seeing what it can become. That is, what can happen when circumstances permit you to evolve or, perhaps, force you to evolve? In my end is my beginning, leading to constant redefinition: re-think, re-imagine, re-discover, and reinvent yourself and/or your institution.

Improving the quality of health care and reducing its costs, requires real innovation with leaders focused less on treating disease and more on systemic changes, i.e., considering health care as an integrated whole calling for revamping by means of innovation [6].

Innovations: Considering innovations in the health care is essential, as the technological opportunities for improved health, the search for better and more equitable services, and the ever swelling costs of health, threaten the economic and social stability of nations worldwide. "It is unlikely that the existing institutions will solve the current problems of the health care. They have to get people who actually know about public health in positions of power" [7].

Continuous Innovation Requires: As Persaud has so aptly put it, in order sciences to continue to improve, we must have 1) Knowledge development adding value by processing existing information to create new knowledge which could be used to define and solve problems. 2) Cross-fertilization of ideas - networking \& physical proximity among well informed people. New knowledge comes from people with time and resources to discuss, think, and experiment. 3) Strong university-industry linkages. 4) Good governance - especially with regards to the legal protection of innovations [8].

A word of caution about expanding too far the lessons from the industry; hospitals do not manufacture anything and the raw material - patients - are defective to start with. Although concepts from non medical sources will be applicable — such as the business value added process, when a patient is admitted and discharged after a sequence of tests and/or procedures are performed - they should be patient centered.

Technology and human capital: The general belief that buildings are important has resulted in new facilities spread around in many towns, schools, universities, hospitals, research centers and even convention centers, without realizing that the quality of the crew - less visible — is the real determining factor for progress. The belief, that increasing buildings and machinery is the fundamental determinant of growth, is sometimes called "capital fundamentalism" by the economists. The conventional wisdom that investing in buildings and machinery is the key to long-run development is another panacea that has not met expectations unless it is combined with human capital - attributes gained by a worker through education and experience. As I have written elsewhere, societies can grow rapidly by relying on a well-trained, educated, hardworking, and conscientious labor force that makes excellent use of modern technologies [9].

Crossing Boundaries, Collaborating for Solutions: Improvement in health care performance requires stakeholders to understand the problems and the need of partnerships among hospitals and with business adopting pathways that can result in clinical solutions for the patient's well-being, as well as combining evidence-based 
standard medicine with complementary care. Translational research and cooperation among sciences, establishing communication vessels, and removing barriers to interdisciplinary alliances, can contribute to finding answers by the exchange of knowledge. The following examples show that medicine is not unique in benefiting from a multidisciplinary environment with its vast quantity of knowledge:

Network Science examines network representations and interconnections in complex systems, of physical, biological, and social phenomena, developing product space maps and analyzing structures of production. It seeks for common principles, and tools that govern network behavior, in order to increase collaboration across disciplines by sharing knowledge. Research is searching for mathematical models to predict performance, according to network size, complexity, and environment [10]. There are several areas outside medicine that can contribute to solving our problems. For example the aviation and space industry provide tools for safety in medicine and rescue operations, etc. Engineering and technology's contribution to the progress of precision medicine and its impact on quality is undeniable. In addition, "Clinical Economics" is a new approach, introducing diagnostic tools from Clinical Medicine for international aid to developing countries in the quests for improvements and grow [11]. And finally, economists, in the wake of the recent global financial crisis, are borrowing tools from other sciences - mathematics, biology, and medicine - in the search for certainty to explain and predict complex systems behavior. To prevent another meltdown, financial regulators may need to focus on the health of networks, not individual banks by thinking more like epidemiologists [12].

\section{Innovative Reforms in Education}

"The commonwealth requires the education of the people as the safeguard of order and liberty", inscription at the Boston Public Library emphasizing the value of education in society.

The Importance of Teaching, training and learning: Needless to say, the intellectual, cultural, and moral benefits of education for individuals and society are undeniable, particularly if it is based in quality rather than quantity. Formal advanced education does not by itself speak to success; it is always what one does with education (or lack thereof) that counts, not the degree itself. "Education is a substantial determinant of success - one of the most relevant — but it is less important than most people think. If everyone had the same education, the inequality of achievements would persist. The consequence of focusing on education alone is to neglect the myriad of other factors that determine people's future" [13].

It would be easy to give a list of many famous and influential people with basic schooling. With this truth in mind, it is important to judge people on the basis of their ability and if possible, without bias. Nevertheless, to prosper, a nation needs a well educated workforce. Efforts to accomplish it should start early before students move forward to university. The countries that get excellent scores in reading, mathematics and science tests - OECD, a club of rich countries - are not necessarily those that spend more. "The variation in achievement cannot be explained by how much is spent but rather to how it is spent. High achieving countries have classes taught by great teachers. They have raised teacher's status by making it harder to become and remain one. Their salaries are according to their quality" [13]. When people are not properly paid, the workplace philosophy inspires: "they pretend to pay us, while we pretend to work."

Which are the industries, professions and professionals that will be needed in the 21 st century? is a question that no one seems able to answer. It is important for societies to attempt to anticipate which sectors are expected to offer the best prospect for the future, therefore, it is the right time to work on the jobs yet to come and thinking seriously about how to prepare our institutions and professionals. This is a challenge not only for Medical Schools, Schools of Public Health and Medical Centers but also for many other disciplines since we are educating young people for jobs that do not even exist just yet with programs of study from the previous century.

Potential new path to success: "In America, only three in 10 young people earn a bachelor's degree by the age of 22, while 40 percent never attend a community college or university. In addition, high schools do not offer alternatives that prepare students to enter the working world. Therefore in a recent report called "Pathways to Prosperity" the authors reason that students could benefit from vocational training to learn the job skills they will need down the road. Just as high schools encourage students to consider college, they should also prepare their graduates to enter apprenticeships, certificate programs, or community colleges that can teach those jobs skills." This pathway could results in a better educated workforce in high-demand fields generating advances in science, health and society that benefit all of us [14].

\section{Education of Health Care Professionals}

Modernizing education even further may be needed at some point in time, moving to a competency based transformative learning. This approach in which knowledge objectives drives the curriculum - requires institutional design as well instructional design curricula-individualizing the process according to specific contexts [15].

The implementation of "twinning programs" is a 
successful tool for improving training, quality, and access to care. Medical schools in all countries have benefited from twinning programs that foster exchange, share resources, and undertake collaborative work for mutual advance. Collaboration, a potent tool of academic systems, describes the opportunities to advance educational quality and output through sharing of information, academic exchange, quest of joint efforts, and synergies between institutions. It ultimately involves the relationship between individuals, but it can be structured and sustained through formalized institutional arrangements that promote, finance, and carry on relationships over time. The institutional objective in education, research, and service can be advanced through sharing of curricula, exchange of faculty, students, and joint research [15].

At the 2005 meeting of the American Board of Thoracic Surgery, a proposal to establish a subspecialty certificate in congenital heart surgery was unanimously approved by the Board of Directors. This proposal was prompted by the recognition that the discipline of congenital heart surgery requires unique skills and education that are not currently provided in a standard thoracic surgery residency. According to this concept, a curriculum is needed to define what skills are required to become an independent surgeon. In addition, education should not be limited to surgical trainees but should also include other related non medical patient caregivers and support services - all members of the health team - moving education beyond interaction only between surgeons to: 1) Attending physicians; 2) Charge nurses/leaders and bedside nurses; 3) Resident/Fellows; 4) Community MDs; 5) Emergency Departments and Outpatient Clinics. Due to the lack of any formal educational process to prepare individuals for the administrative role of a division chief, these efforts should also include those aspiring to these positions in order to promote scholarships in thoracic and cardiovascular surgery. To put it another way, the most important function of the system is the production of the producers.

The teaching-learning process can be improved by linking the matter being taught — whenever possible - to present-day situations in a non-punitive fashion learning oriented error reporting program. Doing so will make it much easier to understand the subject, in addition to making it more pertinent and effective as it relates to today's needs. Furthermore, institutions and professional organizations should be encouraged to use technology to considerably enhance the relevance and quality of education. Unfortunately, everybody gives lip service to education, but only a few are willing to funds it.

Potential Barriers: For many years physicians, and surgeons, have been able to implement new treatments with minimal oversight. As the general public becomes better informed about the inside working of hospitals, medical care, and their doctors, physicians have come under more scrutiny and monitoring than ever before. Society is more critical of the actions of the medical profession. The learning curve has changed, standards are stricter and the measuring sticks more exacting (E. Bove. Seminars in Thoracic and Cardiovascular Surgery, 2003.). In addition, the impact of interventional cardiology and the shift to early repair have resulted in fewer straightforward cases. Furthermore, some common beliefs among surgeons such as, "observing is the best way of learning," "the real surgeon must do the entire case," and "not perceiving that the time spend helping a resident is part of the operation" worsen the situation [16].

\section{Teaching Professionals How to Learn. Not so simple:} "Professionals embody the learning dilemma: they are enthusiastic about continuous improvement - often the biggest obstacle to its success. For them, learning means solving problems by focusing on identifying and correcting errors in the external environment. Managers and employees must also look inward. They need to reflect critically on their own behavior, identify the ways they often inadvertently contribute to the organization's problems and then change how they act." In order to be part of the solution they need to admit that they are part of the problem. For years, General Motors executives became practiced at the art of explaining their problems and attributing blame to everyone but themselves, rather than recognize their inability to admit mistakes [17].

Skilled professionals, almost always successful at what they do, often react defensively blaming others for their problems, in a closed single loop learning that shut down their ability to learn. Persistence of the problems and lack of progress are the consequences of failing backward. There's a difference between defending what you have done than being defensive [17].

Less commonly, smart people are able to learn from failure _ " "failing forward" by using critical thinking and productive reasoning — and this is called double loop learning. Continuous improvement is the result of how they think, design, and implement their actions combining a top down approach with a "bottom up" one [17,18]. It would be hard to accept that maybe people do not want to learn?; Maybe people have not learned how to learn?; Maybe there is a fear of the unknown and therefore the amount and level of stimulation taken in must be inferior to one's own "wisdom"?

National/International Cooperation, Diagnosis and Recipient Selection: Because the world faces many formidable problems, we cannot expect to solve the maldistribution and poor access to cardiac surgery through the regular channels for international aid. Currently, there 
are numerous groups around the world involved with structured international projects, but without coordination among them. In humanitarian medicine, there is room for cooperation rather than competition, because the people in need outnumber those able to provide assistance. Unfortunately, there are not humanitarian solutions for humanitarian problems. Answers that are more comprehensive are needed, in which humanitarianism would play only a part.

To avoid squandering energy and resources it is important to identify places, "fertile sites", and their needs, with receptive individuals where good work is being done. The majority of donor programs focus on developing an ongoing relationship with a host program. This relationship involves visiting teams, teaching, training, collaborative research, and donation of equipment. The "twinning process" results in a transfer of knowledge, ideas and skills and the visiting team usually includes: surgeon, anesthesiologist, cardiologist, perfusionist, critical care specialist, interventional cardiologist, and nurses. To maximize training effectiveness in other cultures, trainers need to understand how cultural differences may affect the expectations of their audiences. Volunteerism, a core value of many peer programs, eventually wears thin as volunteers have other obligations resulting in weakening of early successes. This approach will be most effective when local governments, doctors, and hospitals have a genuine learning interest. In those instances, eventually the host program becomes autonomous, with the donor program assuming a consultant role.

Professional Organizations: Professional organizations can be extremely helpful by coordinating the efforts, and taking maximum advantage of contemporary technology in communications and educational techniques for fostering the transfer of knowledge, skills, and ideas of its members beyond borders for the benefit of patients in lesser-developed countries. In addition to their role in education, lively and energetic local and international professional organizations can respond to the initiatives of the members, to the changes of the specialty and to the evolution of treatment modalities. Professional networks allow physicians to share insights with each other, almost on real time without enduring the unwieldy rules and delays involved in traditional academic publishing [7].

Accreditation: Evaluation of centers, surgeons, training programs and other health professionals: It is necessary to provide a formal recognition to the trainee that has completed the process. National accreditation systems should develop a criterion for assessment, define metrics of output, and shape the competencies of graduates to meet societal health needs. Probably the most difficult and at the same time the most important issue is how to evaluate the genuine technical skills of surgeons, which will not be reflected in references, written examinations and interviews. Professional organizations can arrange visits of a group of experts to evaluate the function of the entire team as well as their training programs through interviews with residents and fellows. Although it is done in some countries it is not yet widely accepted.

\section{Inferences}

- To-date, particularly in developing countries, we have been unable to secure support from governments, professional organizations, philanthropists, patients, or peers for our specialty.

- The existing curriculum of medical schools, developed a century ago, need modernization to produce health care professionals that can adapt to the broad range of therapeutic options offered by the rapidly growing technology.

- Basic sciences may introduce an unthinkable scenario requiring redefinition of the regulatory bodies with a multidisciplinary approach in which innovation should be coupled to early evaluation in order to determine the value of new procedures [19,20].

- Many obstacles remain, but physicians and professional societies can and must play an important role in overcoming them.

\section{Part II will be published in the next issue of the RBCCV \\ Cardiac Surgery: issues around and beyond the operating room}

Ultramini-abstract: In addition to our clinical and technical work, there is a need to cross boundaries searching for collaboration as well as lessons from other complex systems that has identified common solutions for common problems, indicating that the general theory is independent of any particular industry or activity. An innovative partnership among the government, the private sector and foundations can let to major advancement of the health system.

\section{REFERENCES}

1. Willingham D. Trust me, I'm a scientist. Sci Am. 2011;304(5):12.

2. Faust D. History is where the future begins. Harvard Magazine. 2012. p.63. Available at: http://harvardmag.com/pdf/2012/07pdfs/0712-63.pdf

3. Shorow S. A life reborn, a story now told. Harvard University Gazette; 2012. p.16-7. Available at: http://news.harvard.edu/ gazette/story/2012/02/a-life-reborn-a-story-now-told/ 
4. Matloff JM. The practice of medicine in the year 2010. Ann Thorac Surg. 1993;55(5):1311-25.

5. Williams D. Real leadership: helping people and organizations face their toughest, challenges. San Francisco:Berrett-Koehler Publisher; 2005.

6. Berwick D. Institute of health improvement. In: Frieden J, ed. Quality improvement must be included in reform. Elsevier Global Medical News. Thoracic Surgery News; 2009.

7. Christensen CM, Grossman JH, Hwang J. The innovator's prescription: a disruptive solution for health care. New York:Mc Graw Hill;2009.

8. Persaud A. The knowledge gap. Foreign Affairs. 2001;80(2):107-17.

9. Neirotti RA. Cardiac surgery: complex individual and organizational factors and their interactions. Concepts and practices. Rev Bras Cir Cardiovasc. 2010;25(1):VI-VII.

10. Hausmann R, Rodrik D, Velasco A. Competitive advantage of nations growth diagnosis. Boston:Harvard University; 2004.

11. Sachs J. The end of poverty: economic possibilities for our time. New York:Penguin Books; 2006.

12. Power C. Too contagious to fail: why bankers should think more like epidemiologists. Scientific American April 15, 2011.

13. Kahneman D, Krueger AB, Schkade D, Schwarz N, Stone
AA. Would you be happier if you were richer? A focusing illusion. Princeton University. CEPS Working Paper No. 125; May 2006. Available at: http://www.princeton.edu/ ceps/ workingpapers $/ 125 \mathrm{krueger} . \mathrm{pdf}$

14. Symonds W, Schuartz R, Ferguson R. Pathways to prosperity: meeting the challenge of preparing young Americans for the 21 st century. Boston: Harvard University Graduate School of Education; February 2011.

15. Frenk J, Chen L, Bhutta Z, Cohen J, Crisp N, Evans T, et al. Health professionals for a new century: transforming education to strengthen health systems in an interdependent world. Lancet. 2010;376(9756):1923-58.

16. Kron I. Surgical mentoring. Presidential Address. 91st AATS Annual Meeting. Philadelphia;2011.

17. Argyris C. Teaching smart people how to learn. Harvard Business Review; May-June 1991.

18. Maxwell JC. Failing forward turning mistakes into stepping stones for success. Thomas Nelson Inc, April 3, 2007.

19. Berkes F, Colding J, Folke C. Navigating social-ecological systems: building resilience for complexity and change. Cambridge:Cambridge University Press; 2003.

20. McCulloch P, Altman DG, Campbell WB, Flum DR, Glasziou P, Marshall JC, et al. No surgical innovation without evaluation: the IDEAL recommendations. Lancet. 2009;374(9695):1105-12. 